\title{
Analysis of the Internet Information Regarding Reverse total Shoulder Arthroplasty
}

\author{
Mhamad $\mathrm{F}^{1 *}$, Heejoon $\mathrm{A}^{2}$, Barrett $\mathrm{TS}^{3}$, Uri MA ${ }^{4}$ and Nicholas $\mathrm{UA}^{5}$ \\ ${ }^{1}$ Department of Orthopaedic Surgery, USA \\ ${ }^{2}$ Colby University, USA \\ ${ }^{3}$ Department of orthopedic surgery, USA \\ ${ }^{4}$ New Hampshire Spine Institute, USA \\ ${ }^{5}$ Department of Orthopaedic Surgery, USA
}

*Corresponding author: Mhamad F, Department of Orthopaedic Surgery, University Hospitals Case Medical Center, School of Medicine, 11100 Euclid Ave, Cleveland

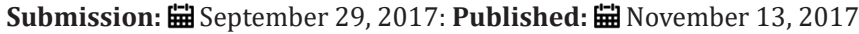

Abstract

Background: Despite its success, reverse total shoulder arthroplasty (RSA) is still a novel procedure, with no long term outcome studies and a significant complication rate. Patients considering RSA should be fully informed about the risks, benefits, and indications for the procedure. Studies have shown that patients use the internet to find medical information and make healthcare decision, sometimes without consulting their provider. Online orthopedic information has been found to be of poor quality in the past.

Purpose: The purpose of this paper is to investigate the online information about RSA and evaluate its quality.

Methods: The authors searched the term "reverse total shoulder replacement" in Google, Yahoo!, and Bing. Sites linking to academic journals were excluded. After discarding duplicates, the top 35 sites in each engine were evaluated. Sites were classified as Academic, Private, Industry or Other. The indications, contraindications, benefits and complications of RSA provided were recorded. Diagrams, descriptions, alternatives, citations and cost information provided were also recorded.

Results: Indications were reported by $95.2 \%$ of all sites, contraindications by $20.95 \%$, benefits by $91.43 \%$ and complications by $38 \%$. Only $18 \%$ of sites reported alternatives, $21.9 \%$ provided citations and $4.7 \%$ mentioned costs. A description of the procedure was provided by $89.5 \%$ of sites and diagrams were provided by $46.67 \%$.

Conclusion: Sites more frequently reported benefits and indications than contraindications and complications. Sites rarely reported alternatives or provided citations. There are gaps in the online information about RSA, which seems to be geared towards marketing rather than informational purposes.

\section{Introduction}

Conventional total shoulder replacements (TSA) are implanted with the goal of replicating and restoring the functional anatomy of an arthritic glenohumeral joint [1]. In the majority of patients this procedure provides excellent pain relief and restoration of function $[1,2]$. Patients with a combination of glenohumeral arthritis and a massive rotator cuff tear, however, have been historically more difficult to treat and experience relatively unsatisfactory results with a TSA [1-3]. This condition, known as cuff tear arthropathy (CTA), is currently a major indication for a reverse total shoulder arthroplasty (RSA) [1-5]. RSA has been utilized in Europe for this condition since the late 1980s and received FDA approval in 2004. Since its approval its indications have expanded in the United States and it has been used, with successful results, in the treatment of fracture sequelae, revision of failed TSAs, tumors, rheumatoid arthritis and instability $[5,6]$.

While RSA has provided a successful treatment modality for these conditions, it is a new procedure in the United States and there are currently no long term studies on outcomes and prosthesis survival [4,5]. Additionally RSA is a highly technical procedure with significant complications. Reported complication rates vary widely, from $15 \%$ to $50 \%$ [3,6-8]. Given the novelty of RSA, its lack of long term data, and disputed complication rates it is imperative that patients considering it as a treatment option are fully informed about the risks, benefits, and indications regarding the procedure. Today, the Internet provides a readily available source of medical information for patients outside of their physician's office. 
Liszka et al. [9] found that 79\% of patients had used the internet to find health-care related information, $73 \%$ had used that information to make a health care decision and only $50 \%$ had shared the information with their health care provider. Additionally previous studies have evaluated the quality of orthopedic health care information available on the Internet and found it to either be of poor quality or aimed towards marketing rather than informational [10-13]. To the author's knowledge there is currently no published evaluation of the information regarding RSA available on the Internet. The purpose of this paper is to investigate the information regarding RSA available to patients on the Internet.

\section{Methods}

Our study design attempted to replicate the patient Internet search experience as closely as possible. The three most commonly used search engines were identified: Google, Yahoo!, and Microsoft Bing. The authors searched the term "reverse total shoulder replacement" in each search engine. The top 35 sites identified using each search engine were analyzed to compile a total data set of 105 sites consistent with the numbers evaluated in prior studies [12]. Duplicate sites were discarded, as were sites that were identical with the exception of URL. Sites directly linking to publications in academic journals were excluded. Sites linking to physical therapy protocols with no information about the procedure itself were discarded. Our search was carried out using a naïve internet browser to limit bias from prior medically related browsing history, and location services for each search engine were disabled to reduce geographic impact on search results. Additionally, search history was cleared between using different search engines to maintain a naïve internet browser.

Each site was evaluated on the basis of sponsorship. Sites were classified into one of four categories: Academic, Private, Industry, or Other. Sites sponsored by accredited universities or university affiliated healthcare institutions were defined to be Academic. Sites sponsored by a privately operating physician or group of physicians, or sites sponsored by a private corporation and edited by a privately operating physician or group of physicians were classified as Private. Sites sponsored by biomedical device corporations were considered to be Industry. Sites falling outside of these three categories were categorized as other. These sites included online large online databases not sponsored or edited by a physician or physician group, sites specific to reverse total shoulder replacements or orthopedics without sponsorship or editing by a physician or physician group, and sites sponsored by insurance companies.

Appropriate indications for reverse total shoulder replacements outlined by each site were recorded. Indications for RSA according to published literature are cuff tear arthropathy, inflammatory arthropathy with massive rotator cuff tear, proximal humeral nonunion or mal union, acute fractures, fixed glenohumeral dislocation, posttraumatic arthritis, tumor, revision arthroplasty, chronic pseudo paralysis without arthritis, rheumatoid arthritis, and aseptic necrosis in the elderly population $[4,5,14]$.
Appropriate contraindications reported by each site were also recorded. Contraindications to this procedure are deltoid impairment, axillary nerve palsy, a rotator cuff tear without arthritis and full or nearly full elevation, and a young, active patient $[4,5]$.

Benefits offered and potential complications reported by sites were recorded on an individual basis, and total numbers of benefits and complications discussed per site were tabulated. Alternative treatments discussed by each site were recorded on an individual basis, and whether they discussed surgical or non surgical treatment options was recorded and tabulated. References offered by each site were analyzed and assigned to one of three categories: Peer-Reviewed Literature, American Experience, or International Experience. Statistics based on experiential interaction with American patient populations without reference to published data as well as references to other websites were classified as American Experience. Analogous reports by international groups were classified as International Experience. Whether sites had descriptions of the procedure or diagrams illustrating the procedure was recorded. As we did not consider patient interpretation of data likely to be influenced by the date of most recent information update, we did not account for the date of the last update of each site.

\section{Results}

A total of 105 sites were evaluated from the Internet search. Of those sites $24(22.85 \%)$ were academic, $70(66.67 \%)$ were private, $4(3.8 \%)$ were industrial and $7(6.67 \%)$ were other. One hundred of the 105 sites $(95.2 \%)$ provided an indication for RSA. All of the academic and industrial sites reported indications, while $95.3 \%$ of private sites and $85.7 \%$ of other sites reported indications. Contraindications were reported by a total of 22 sites (20.95\%). Contraindications were reported by $20.83 \%$ of academic sites, $17.14 \%$ of private sites, $50 \%$ of industrial sites and $42.8 \%$ of other sites. Benefits of RSA were reported by a total of 96 sites $(91.43 \%)$, while complications were reported by only 40 sites (38\%). Industrial sites reported benefits and complications at the highest rate, at $100 \%$ and $75 \%$ respectively. Private sites had the lowest rate of reporting complications at 30\%. They reported benefits, however, at the second highest rate of $94.3 \%$.

Of the sites that reported benefits of RSA the academic sites reported an average of 2.09 benefits, the private sites reported an average of 2.83, industrial sites reported an average of 2.25 and other sites reported an average of 2 benefits. Of the sites that reported complications of RSA the academic sites reported an average of 4 , private sites reported an average of 4.19, industrial sites reported an average of 5.67 and other sites reported an average of 6.25 complications. Commonly reported benefits included pain relief, increased range of motion (ROM), improved shoulder function, increased ability to perform activities of daily living (ADL) and improved shoulder stability.

Frequently reported complications included fracture, dislocation, loosening of components, infection, scapular notching, 
hardware failure, hematomas, and neurovascular damage. A total of 19 sites (18\%) reported alternatives to RSA. Twenty-three sites $(21.9 \%)$ provided citations for their data, and 5 sites $(4.7 \%)$ mentioned the cost of the procedure. A total of 49 sites (46.67\%) had diagrams of the procedure and 94 sites (89.5\%) provided a description of RSA.

\section{Discussion}

Private physicians or physician groups sponsored the majority of websites that we evaluated (66.67\%), while academic institutions sponsored the second largest group of evaluated sites $(22.85 \%)$. It would seem that physicians have a great degree of control over the online information available to the public regarding RSA. Descriptions of the procedure, as well as indications for RSA, were reported at a high rate $(89.5 \%$ and $95.2 \%$, respectively). Furthermore commonly reported indications were in accordance with published literature and included CTA, massive irreparable rotator cuff tears, rheumatoid arthritis, tumors, pseudo paralysis, revision of failed replacements, and treatment of fracture sequelae $[1-5,14]$.

Contraindications, by comparison, were reported at a much lower rate of $20.9 \%$. Private sites reported contraindications at the lowest rate of $17.14 \%$. The reported contraindications, however, were accurate when compared to the published literature and included active infection, an impaired deltoid muscle, axillary nerve palsy, a young active patient, and a lack of sufficient glenoid bone stock $[5,15,16]$. Similarly, benefits of RSA were reported at a much higher overall rate than complications (91.4\%) and 38\%, respectively). The private data had the lowest rate of reporting complications at $30 \%$. The benefits of RSA were consistent with those reported in the literature based on shoulder scoring scales utilized in clinical practice and include pain relief, increased ROM, stability, strength, improved function and increased ability to perform ADL [2,3,14-17]. Complications were also consistent with those reported in the literature and included infection, dislocation, fracture, neurovascular damage, hematoma formation, loosening of components and hardware failure [1-14]. The discrepancy between the rates of reporting positive parameters (indications and benefits) and negative parameters (contraindications and complications) suggests that websites, especially those sponsored by private groups, are more focused on marketing rather than providing all of the information pertinent to the procedure. This is consistent with previous studies that have reported that websites are geared towards marketing rather than disseminating information [13].

Additionally, it is troubling that such a small percentage of sites $(18 \%)$ reported any alternative treatments to RSA. Important alternatives to consider are conservative treatments such as rest, activity modification, anti-inflammatory medication, physical therapy, and corticosteroid injection. The published literature reports that RSA is only performed after six months of failed conservative treatment [2-6]. It is our opinion that this was not adequately represented in the information present online. Costs of the procedure were reported at a very low rate $(4.7 \%)$. While this could be attributable to variations in price it can also be seen as another failure to put information that is not marketable online. Websites cited their information at a rate of only $21.9 \%$. Providing citations to the literature or patient experiences would be a simple method to make more information available to the general population and provide direction to reputable sources of information (Table 1-6).

Table 1: Number of sites that published information about each of the parameters we evaluated, broken down by site sponsorship.

\begin{tabular}{|c|c|c|c|c|c|c|}
\hline Parameter & Academic & Private & Industrial & Other & Total & Total percent \\
\hline Total sites & 24 & 70 & 4 & 7 & 105 & - \\
\hline Any indication & 24 & 66 & 4 & 6 & 100 & $95.24 \%$ \\
\hline Any contraindication & 5 & 12 & 2 & 3 & 22 & $20.95 \%$ \\
\hline Any benefit & 21 & 66 & 4 & 5 & 96 & $91.43 \%$ \\
\hline Any complication & 12 & 21 & 3 & 4 & 40 & $38.10 \%$ \\
\hline Alternatives & 7 & 11 & 0 & 1 & 23 & $21.90 \%$ \\
\hline Citations & 7 & 9 & 3 & 4 & 5 & $4.76 \%$ \\
\hline Cost & 0 & 3 & 0 & 2 & 49 & $46.67 \%$ \\
\hline Diagrams & 16 & 28 & 3 & 6 & 94 & $89.52 \%$ \\
\hline Descriptions & 22 & 63 & 3 & & & 23 \\
\hline
\end{tabular}

Table 2: Average number of benefits and complications reported by websites, broken down by site sponsorship.

\begin{tabular}{|c|c|c|}
\hline Site Sponsor & Average No. of Benefits Reported & Average No. of Complications Reported \\
\hline Academic & 2.09 & 4.19 \\
\hline Private & 2.83 & 5.67 \\
\hline Industrial & 2.25 & 6.25 \\
\hline Other & 2 & 4 \\
\hline
\end{tabular}


Table 3: Number of sites that listed individual benefits of RSA, broken down by site sponsorship.

\begin{tabular}{|c|c|c|c|c|}
\hline Site Sponsor & Pain Reduction & Increased ROM & Increased Function & 4 \\
\hline Academic & 13 & 16 & 10 & 3 \\
\hline Private & 42 & 45 & 0 & 10 \\
\hline Industrial & 2 & 3 & 0 & 2 \\
\hline Other & 5 & 3 & 14 & 2 \\
\hline Total & 62 & 67 & 24 \\
\hline
\end{tabular}

Table 4: Number of sites that listed individual complications of RSA, broken down by site sponsorship.

\begin{tabular}{|c|c|c|c|c|c|c|c|c|c|c|}
\hline $\begin{array}{c}\text { Site } \\
\text { Sponsor }\end{array}$ & Infection & Dislocation & Fracture & $\begin{array}{l}\text { Shoulder } \\
\text { Instability }\end{array}$ & $\begin{array}{l}\text { Component } \\
\text { Loosening }\end{array}$ & Notching & $\begin{array}{c}\text { Hardware } \\
\text { Failure }\end{array}$ & Hematoma & $\begin{array}{c}\text { Neurovascular } \\
\text { Damage }\end{array}$ & Other \\
\hline Academic & 8 & 8 & 5 & 3 & 5 & 2 & 2 & 2 & 6 & 7 \\
\hline Private & 12 & 10 & 7 & 7 & 12 & 5 & 4 & 4 & 5 & 22 \\
\hline Industrial & 3 & 3 & 1 & 1 & 3 & 0 & 0 & 2 & 0 & 4 \\
\hline Other & 4 & 3 & 3 & 3 & 2 & 0 & 2 & 0 & 3 & 5 \\
\hline Total & 27 & 24 & 16 & 14 & 22 & 7 & 8 & 8 & 14 & 38 \\
\hline
\end{tabular}

Table 5: Percentage of sites that provided alternatives to RSA, broken down by site sponsorship.

\begin{tabular}{|c|c|c|c|}
\hline Site Sponsor & Any Alternative (\%) & Surgical Alternative (\%) & $8.33 \%$ \\
\hline Academic & $29.16 \%$ & $2.85 \%$ & $14.28 \%$ \\
\hline Private & $15.71 \%$ & $0.00 \%$ & $0.00 \%$ \\
\hline Industrial & $0.00 \%$ & $14.20 \%$ \\
\hline
\end{tabular}

Table 6: Percentage of sites that provided citations, broken down by site sponsorship.

\begin{tabular}{|c|c|c|c|}
\hline Site Sponsor & Peer Reviewed Literature (\%) & American Experience (\%) & $4.16 \%$ \\
\hline Academic & $25.00 \%$ & $2.85 \%$ & $0.00 \%$ \\
\hline Private & $5.71 \%$ & $25.00 \%$ & $0.00 \%$ \\
\hline Industrial & $50.00 \%$ & $14.20 \%$ \\
\hline Other & $42.85 \%$ & $0.00 \%$ & $0.00 \%$ \\
\hline
\end{tabular}

\section{Conclusion}

Our study shows a discrepancy in the information presented online in regard to RSA. Websites provide information on the positive aspects of RSA such as benefits and indications for treatment at a much higher rate than negative aspects such as contraindications, complications and cost. This bias in information suggests that while the information presented on websites about RSA is accurate, it is designed for marketing purposes rather than informing the patient. It is imperative that patients are fully informed while making healthcare decisions and most of the information available online is not adequate in this regard. It may be assumed that patients will discuss any treatment options with their doctor before pursuing any particular procedure.

However this is not necessarily the case as research has shown that patients make healthcare decisions based on information found online, sometimes without sharing that information with their doctor [9]. Academic and private physician groups have a large degree of control over the online information about RSA available to the general public. As such it is important that physicians provide information online that is less biased in order to better inform patients considering RSA as a treatment option. Additionally, physicians should be aware of the limitations of the information available on the Internet and provide their patients with balanced sources of information about RSA.

\section{References}

1. Smithers CJ, Young AA, Walch G (2011) Reverse shoulder arthroplasty. Curr Rev Musculoskelet Med 4(4):183-190.

2. Boileau P, Watkinson D, Hatzidakis AM, Hovorka I (2006) Neer Award 2005: The Grammont reverse shoulder prosthesis: results in cuff tear arthritis, fracture sequelae, and revision arthroplasty. J Shoulder Elbow 15(5): 527-540 
3. Mulieri P, Dunning P, Klein S, Pupello D, Frankle M (2013) Reverse shoulder arthroplasty for the treatment of irreparable rotator cuff tear without glenohumeral arthritis. J Bone Joint Surg Am 92(15): 25442556.

4. Scarlat MM (2013) Complications with reverse total shoulder arthroplasty and recent evolutions. Int Orthop 37(5): 843-851.

5. Drake GN, OConnor DP, Edwards TB (2010) Indications for reverse total shoulder arthroplasty in rotator cuff disease. Clin Orthop Relat Res 468(6): 1526-1533.

6. Wall B, Nove JL, OConnor DP, Edwards TB, Walch G (2007) Reverse total shoulder arthroplasty: a review of results according to etiology. J Bone Joint Surg Am 89(7): 1476-1485.

7. Werner C, Steinmann P, Gilbart M, Gerber C (2005) Treatment of painful pseudoparesis due to irreparable rotator cuff dysfunction with the Delta III reverse-ball-and-socket total shoulder prosthesis. J Bone Joint Surg Am 87(7): 1476-1486

8. Zumstein M, Pinedo M, Old J, Boileau P (2011) Problems, complications, reoperations, and revisions in reverse total shoulder arthroplasty: a systematic review. J Shoulder Elbow Surg 20(1): 146-157.

9. Liszka HA, Steyer TE, Hueston WJ (2006) Virtual Medical Care: How Are Our Patients Using Online Health Information? J Community Health 31(5): 368-378.

10. Gustafson DH, McTavish F, Hawkins R, Pingree S, Arora N, et al. (1998)
Computer support for elderly women with breast cancer. JAMA 280(15): 1305.

11. Beredjiklian PK, Bozentka DJ, Steinberg DR, Bernstein J (2000) Evaluating the Source and Content of Orthopaedic Information on the Internet The Case of Carpal Tunnel Syndrome. J Bone Joint Surg Am 82A(11): 1540-1543.

12. Morr S, Shanti N, Carrer A, Kubeck J, Gerling MC (2010) Quality of information concerning cervical disc herniation on the Internet. Spine J 10(4): 350-354.

13. Qureshi SA, Koehler SM, Lin JD, Bird J, Garcia RM, et al. (2012) An evaluation of information on the internet about a new device: the cervical artificial disc replacement. Spine 37(10):881-883.

14. Jazayeri R, Kwon YW (2011) Evolution of the reverse total shoulder prosthesis. Bull NYU Hosp Jt Dis 69(1):50-55.

15. Seebauer L, Walter W, Keyl W (2005) Reverse total shoulder arthroplasty for the treatment of defect arthropathy. Oper Orthop Traumatol 17(1): $1-24$.

16. Frankle M, Levy J, Pupello D, et al. (2006) Prosthesis for Glenohumeral Arthritis Associated with Severe Rotator Cuff Deficiency. The Journal of Bone \& Joint Surgery 88-A: 178-190.

17. Romeo AA, Mazzocca A, Hang DW, Shott S, Bach BR (2004) Shoulder Scoring Scales for the Evaluation of Rotator Cuff Repair. Clin Orthop Relat Res 427: 107-114. 